\title{
APPLICATION OF VALUE ANALYSIS METHODOLOGY ON DIVAN BED
}

\author{
Neha Nadiger \\ Pre-final Year Engineering student \\ Bangalore Institute of Technology, \\ KR Road, V.V Puram, Bangalore, India
}

\begin{abstract}
Value Engineering is an organized, creative problem-solving approach to identify the unnecessary costs in Functional Areas and to increase the Return -onInvestment. A critical study is done on a Divan Bed in which the product is modified according to Value Engineering techniques. This paper introduces the application of theories and phases of Value Engineering in the design of Divan Bed. This paper focuses on Functional Enhancement of Divan Bed. We thereby use techniques like Functional Analysis, Functional Evaluation and Decision Matrix to arrive at a feasible alternative. With the aim of increasing functionality, the conventional material of wood used for the manufacturing of Divan Bed is replaced with polypropylene material. This study results in the Divan Bed being convertible to a table and a chair.
\end{abstract}

KEYWORDS: Value Engineering, Functional Areas, ReturnOn-Investment, Decision Matrix, Design of Divan Bed.

\section{INTRODUCTION}

Value Analysis is defined as an organised effort directed at analysing the functions of systems, equipment, facilities, service and supplies for the purpose of achieving the essential functions at the lowest life-cycle cost, consistent with required performance, quality, reliability and safety.

\section{CONCEPT OF VALUE}

Value is the lowest possible cost of a product or a service performing a useful and essential function with required quality and reliability.
Amogh Bhaskar.

Pre-final Year Engineering student. Bangalore Institute of Technology, KR Road,V.V Puram, Bangalore, India

- Value $=$ Function

Cost

To Increase Value

$$
\begin{array}{ll}
\frac{\mathrm{F} \uparrow}{\mathrm{C}} \quad \frac{\mathrm{F} \uparrow}{\mathrm{C}} \rightarrow \quad \frac{\mathrm{F}}{\mathrm{C}} \rightarrow \frac{\mathrm{F} \uparrow}{\mathrm{C}} \uparrow \\
\downarrow \text { REDUCE } \quad \uparrow \text { INCREASE } \longrightarrow \text { MAINTAIN }
\end{array}
$$

III. OBJECTIVES OF VALUE ENGINEERING

- To deliver the product or service in a cost-effective way.

- To reduce Lead Time.

- To minimize Risks.

- To assure Quality.

- To enhance Profitability.

- To improve serviceability

\section{OBJECTIVES OF THE RESEARCH PAPER}

Divan Bed is the one of the commonly used furniture in a household. With this project, we intend to bring about multiple functions in the same Divan Bed. The proposed product enables us to use the Divan Bed as a table and a chair. We see a huge dip in pricing of the product thus making it cost effective. The objectives can be summarised as:

- Improve functionality of the existing product.

- Ensure better consumer satisfaction

- Uplift profitability of the organization.

\section{INFORMATION PHASE}

This is the first phase in Value Methodology in which all the relevant information regarding the project is gathered. 
The available information of Divan Bed was collected from various sources and the summary is reproduced below:

Product: Divan Bed

Material:

Wood, Plastic, Iron, Aluminium, Steel. Standard dimensions: $\quad 30^{\prime} 00^{\prime \prime} \times \quad$ X $63^{\prime \prime}$. Purpose: Sit, Rest Present

Cost: Rs. 2026/-

Weight: $25-30 \mathrm{Kg}$

Assembly and Design: No extra assembly and set-up require

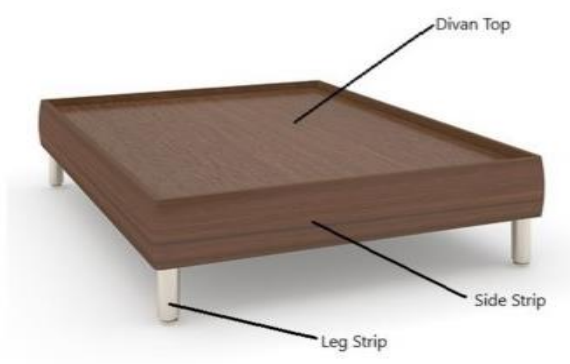

VI. MANUFACTURING OF A DIVAN BED:

1) The pipes required for the manufacturing of the Bed is stored in pipe store.

2) The pipes are taken to the pipe cutting machine and cut to dimensions for leg strips.

3) The boards used for the parts of the Bed are stacked in the board stacking area.

4) These boards are taken to the board cutting machine and cut according to dimensions.

5) The parts are then taken to the edge banding machine to cut the edges.

6) Inspection of the parts.

7) Assembly of the parts.

\section{FUNCTIONAL PHASE}

According to Lawrence. D. Miles, "The basic purpose of each expenditure is to fulfil a function." The success of Value Analysis depends on careful analysis of the functions of the assembly/components. The objective is to clearly identify the tasks to be carried out by the assembly components. The functions are classified as Basic or Secondary. A function is Basic if it is the prime or specific purpose for which the assembly or components were designed. A function is Secondary if it does not directly contribute to the basic function or it is only required to support the achievement of the basic function.

Function Analysis Table:

Detailed

Function Analysis of different parts of Divan as shown in the table below

\begin{tabular}{|c|c|c|c|c|c|}
\hline \multirow{2}{*}{ PART NAME/DESCRIPTION } & \multirow{2}{*}{ QUANTITY } & \multicolumn{2}{|c|}{ FUNCTION } & \multicolumn{2}{|c|}{ PART } \\
\hline & & VERB & NOUN & BASIC & SECONDARY \\
\hline \multirow{4}{*}{ Wooden FRAME(COMPLETE) } & \multirow{4}{*}{1} & Hold & Assembly & $\mathrm{x}$ & \\
\hline & & Hold & Parts & & $x$ \\
\hline & & Provide & Strength & & $\mathrm{x}$ \\
\hline & & Provide & Grip & & $x$ \\
\hline \multirow{3}{*}{ Bed Top(Divan Top) } & \multirow{3}{*}{1} & Hold & Material & & $x$ \\
\hline & & Provide & Surface & $\mathrm{x}$ & \\
\hline & & Improve & Appearance & & $x$ \\
\hline \multirow{2}{*}{ Side Strip ( Long) } & \multirow{2}{*}{2} & Support & Frame & & $x$ \\
\hline & & \begin{tabular}{|l} 
Improve \\
\end{tabular} & Appearance & & $x$ \\
\hline \multirow[b]{2}{*}{ Side Strip(Short) } & \multirow[b]{2}{*}{2} & Support & Frame & & $x$ \\
\hline & & Improve & Appearance & & $x$ \\
\hline \multirow[b]{2}{*}{ Leg Strip } & \multirow[b]{2}{*}{4} & Support & Frame & & $\mathrm{x}$ \\
\hline & & Improve & Appearance & & $\mathrm{x}$ \\
\hline
\end{tabular}

Table 1: Function Analysis worksheet

Functional Evaluation- Detailed Functional Evaluation Of different parts of divan bed with weight and percentage cost in the product as shown in the table

\begin{tabular}{|l|l|l|l|}
\hline Key Letter & Part & Function & \% Cost \\
\hline A & $\begin{array}{l}\text { Wooden Frame } \\
\text { (Complete) }\end{array}$ & Hold Assembly & 32.43 \\
\hline B & $\begin{array}{l}\text { Bed Top (Divan } \\
\text { Top) }\end{array}$ & $\begin{array}{l}\text { Provide } \\
\text { surface }\end{array}$ & 30.47 \\
\hline C & Side Strip (Long) & $\begin{array}{l}\text { Support } \\
\text { Frame }\end{array}$ & 24.90 \\
\hline D & Side Strip (Short) & $\begin{array}{l}\text { Support } \\
\text { Frame }\end{array}$ & 7.28 \\
\hline E & Leg Strip & $\begin{array}{l}\text { Improve } \\
\text { Appearance }\end{array}$ & 4.92 \\
\hline
\end{tabular}

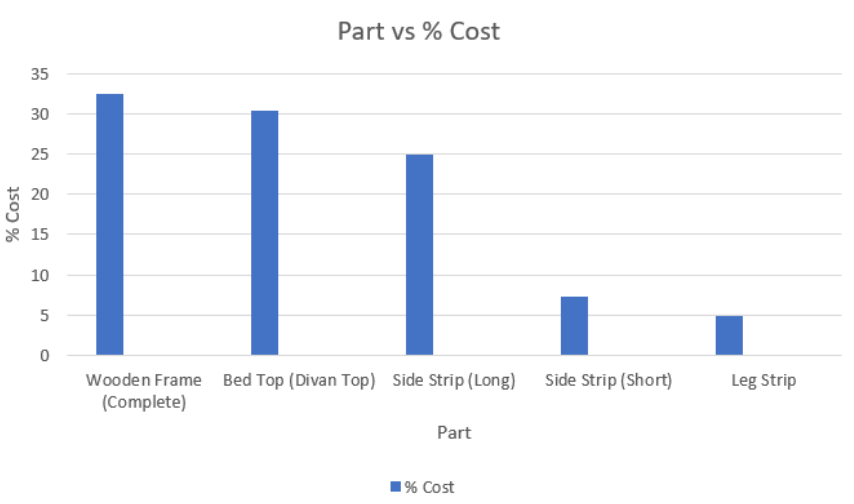


Costing of different parts of divan as shown in the table below:

\begin{tabular}{|l|l|l|l|}
\hline Sr. No & Part & Quantity W W W N & \\
\hline A & $\begin{array}{l}\text { Wooden Frame } \\
\text { (Complete) }\end{array}$ & 1 & Weight \\
\hline B & $\begin{array}{l}\text { Bed Top (Divan } \\
\text { Top) }\end{array}$ & 1 & 565.00 \\
\hline C & Side Strip (Long) & 2 & 480.00 \\
\hline D & Side Strip (Short) & 2 & 211.00 \\
\hline E & Leg Strip & 4 & 175 \\
\hline & \multicolumn{2}{|c|}{ Total } & 2026.00 \\
\hline
\end{tabular}

Table 2: Total Costing of divan bed parts

\section{Numerical Evaluation Sheet:}

A

\begin{tabular}{|c|c|c|c|}
\multicolumn{1}{c}{ B } & \multicolumn{1}{c}{ C } & D & E \\
\hline A3 & A3 & A3 & A3 \\
\hline \multirow{2}{*}{ B } & B2 & B2 & B2 \\
\cline { 2 - 4 } & C & C1 & C1 \\
\cline { 3 - 4 } & & D & D1 \\
\cline { 3 - 4 } & &
\end{tabular}

12
6
2
1
1

Major Performance-3

Medium Performance- 2

Minor Performance- 1

\section{CREATIVE PHASE}

The main agenda of the creative phase is to remodel the Divan Bed to provide increased functions which also prove to be cost effective. "Challenge Everything" is the cardinal principle of value Engineering. Accordingly, a brainstorming session was held to generate alternative ideas by thinking creatively and positively. The below listed are some of the optimum alternatives: 1) Designing the Divan Bed using particle board. 2) Foldable Bed, 3) Moulded plastic Bed. 4) Multi -purpose polypropylene frame - Bed, chair \& table.

\section{EVALUATION PHASE}

The evaluation phase enables us to select the most feasible ideas which also meet the required criteria. We have listed the advantages and the disadvantages of the preferred alternatives. Rank each idea from 1 to 10 for the below shown factors. We use judicial ability for ranking and discard non- feasible ideas.

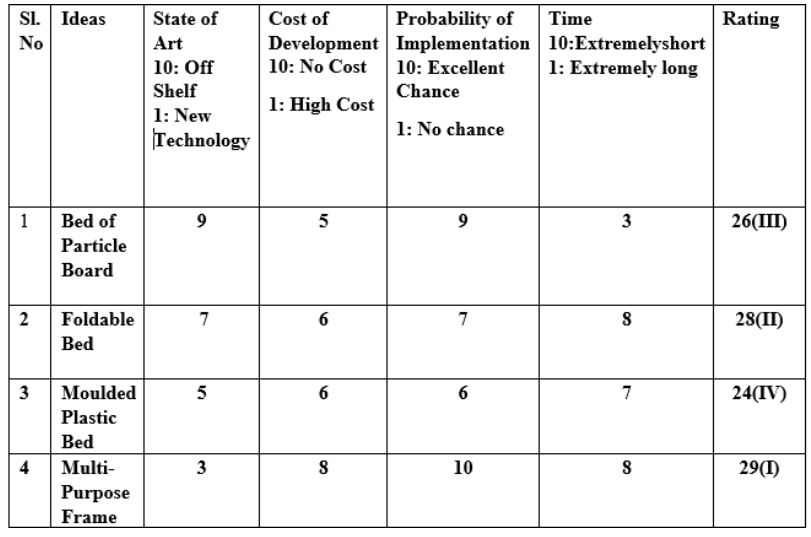

The evaluation of the above four ideas against five parameters to check feasibility

\begin{tabular}{|c|c|c|c|c|}
\hline Ideas $\rightarrow$ & & & & \\
\hline $\begin{array}{c}\text { Parameters } \\
\downarrow\end{array}$ & 1 & 2 & 3 & 4 \\
\hline Durability & 1 & 1 & 1 & 1 \\
\hline $\begin{array}{l}\text { Maintenance } \\
\text { Requirement }\end{array}$ & 1 & 0 & 0 & 0 \\
\hline Appearance & 0 & 0 & 0 & 1 \\
\hline Ease of Use & 1 & 1 & 1 & 1 \\
\hline Compactness & 0 & 1 & 0 & 1 \\
\hline Total & 3 & 3 & 2 & 4 \\
\hline$\%$ & 60 & 60 & 40 & 80 \\
\hline
\end{tabular}

Table 4: Evaluation of Ideas

1- YES 0-NO

\section{DEVELOPMENT PHASE}

This phase allows the manufacturers to determine the most preferred alternatives amongst the various proposed alternatives. Advantages and Disadvantages are listed and ranked to determine which alternative should be implemented. 
International Journal of Engineering Applied Sciences and Technology, 2019

Vol. 4, Issue 8, ISSN No. 2455-2143, Pages 199-204

Published Online December 2019 in IJEAST (http://www.ijeast.com)

\begin{tabular}{|c|c|c|c|c|}
\hline Sl. No & Ideas & Ranking & Advantages & Disadvantages \\
\hline 1 & Foldable bed & 2 & $\begin{array}{c}\text { Efficient use of } \\
\text { space } \\
\text { Easy Handling }\end{array}$ & $\begin{array}{c}\text { Careful } \\
\text { Maintenance }\end{array}$ \\
\hline 2 & $\begin{array}{c}\text { Multi-purpose } \\
\text { frame }\end{array}$ & 1 & $\begin{array}{c}\text { Multi-purpose } \\
\text { Light Weight } \\
\text { Mobile }\end{array}$ & Low strength \\
& \multicolumn{2}{|c|}{} & & Table 7: Ranking of preferred ideas \\
\hline
\end{tabular}

Key Criteria: Evaluation of two alternatives is done by considering the below stated factors:

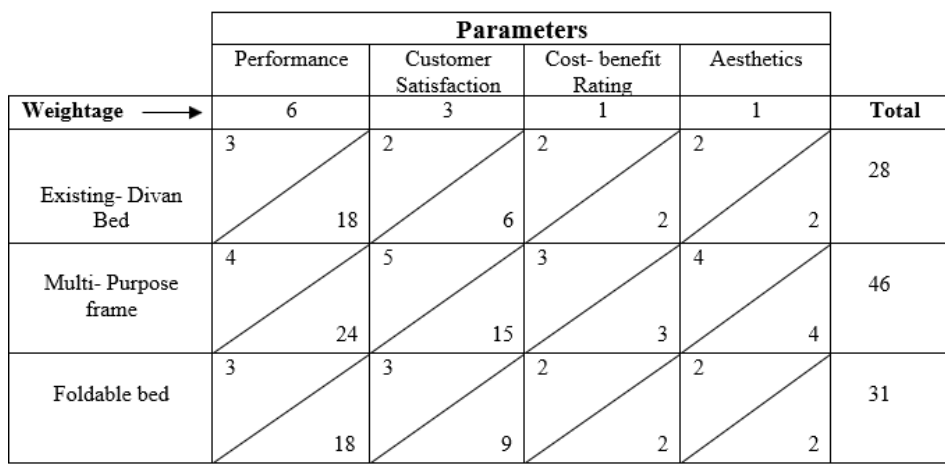

\begin{tabular}{|c|c|}
\hline 5 & Excellent \\
\hline 4 & Very Good \\
\hline 3 & Good \\
\hline 2 & Fair \\
\hline 1 & Poor \\
\hline
\end{tabular}

\section{RECOMMENDATION PHASE}

The Evaluation Matrix indicated that alternative of MultiPurpose Polypropylene frame is preferred to the existing product and to the folding Bed. The function benefit analysis is done for the preferred alternative and the existing one as shown below:

\begin{tabular}{|c|c|}
\hline $\begin{array}{c}\text { Situation Before- Existing } \\
\text { Product }\end{array}$ & $\begin{array}{c}\text { Situation After- Multi } \\
\text { Purpose Polypropylene } \\
\text { Frame }\end{array}$ \\
\hline Heavier & Lighter \\
\hline Single Use & $\begin{array}{c}\text { Can be used as a chair, } \\
\text { table as well as the bed- } \\
\text { Multi Use }\end{array}$ \\
\hline Less Economical & More Economical \\
\hline $\begin{array}{c}\text { More manufacturing cost and } \\
\text { raw material cost }\end{array}$ & $\begin{array}{c}\text { Less manufacturing cost } \\
\text { and raw material cost. }\end{array}$ \\
\hline
\end{tabular}

\section{Table 10: Comparison Table}

\section{PRESENTATION PHASE}

This phase presents the function-based creativity in the chosen product along with the monetary aspects.

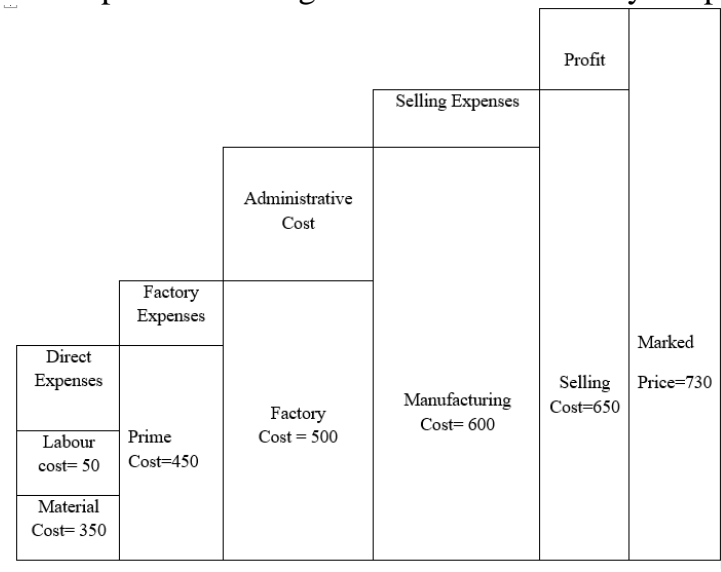

Table 11: Prime cost split-up for the proposed alternative

\begin{tabular}{|c|c|}
\hline Present Cost (Rs) & 2026 \\
\hline Proposed Cost (Rs) & 730 \\
\hline Saving (Rs) & 1296 \\
\hline \% Saving & 64 \\
\hline
\end{tabular}


International Journal of Engineering Applied Sciences and Technology, 2019

Vol. 4, Issue 8, ISSN No. 2455-2143, Pages 199-204

Published Online December 2019 in IJEAST (http://www.ijeast.com)

XIII. ILLUSTRATIONS OF PROPOSED ALTERNATIVE
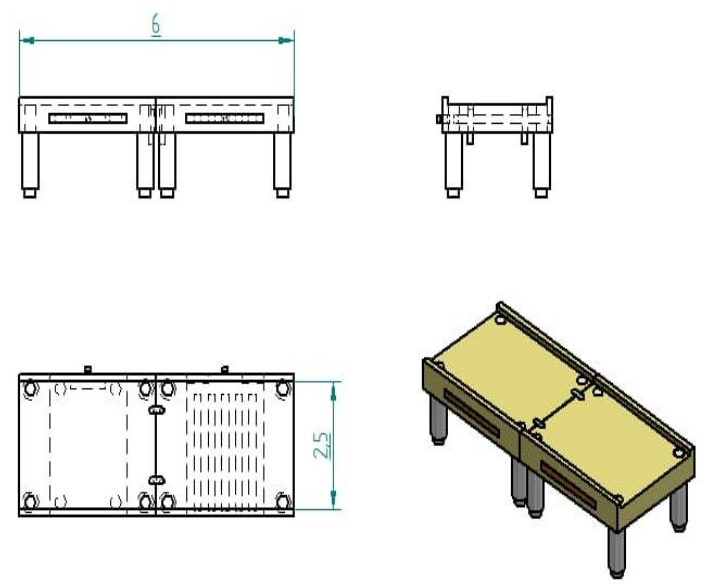

all dimension are in feet

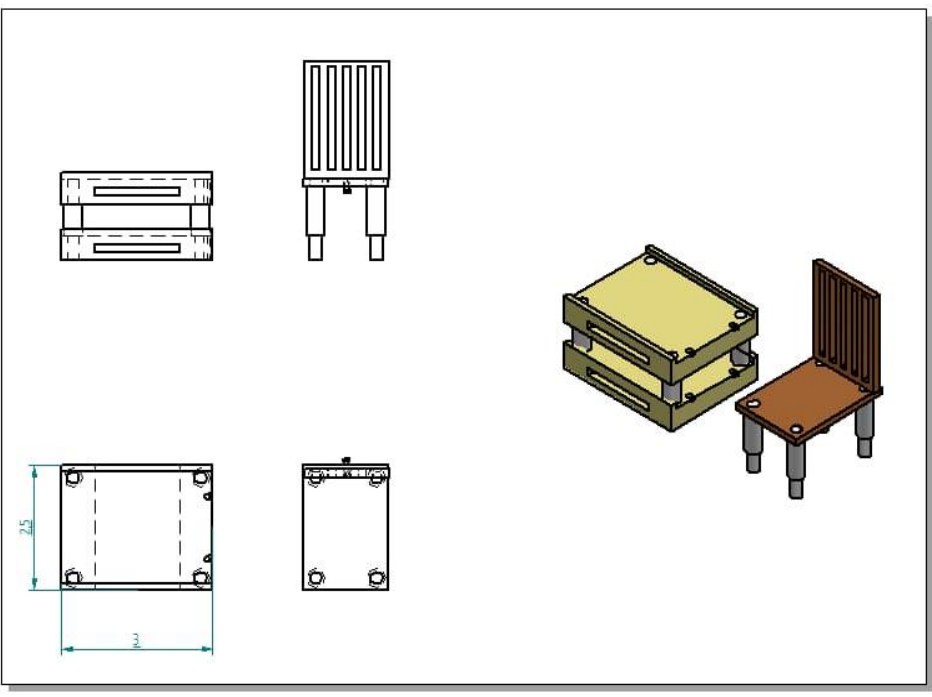

XIV.

\author{
KEY POINTS ON IMPLEMENTATION \\ - Improved Space Usage \\ - Higher Return-on-Investment \\ - Increased functionality \\ - Better Ergonomics \\ - Higher Consumer Satisfaction \\ - Lesser Lead time \\ - Reduced Manufacturing cost \\ - Use of alternative materials
}

\section{CONCLUSIONS}

The Value Engineering process and procedures are generally well-defined and well understood at all levels in the industry. Value Engineering has well formulated techniques of evaluation of cost and functions of the product considering key criteria like consumer satisfaction, durability, time lead and so on. From the study, we have tried to implement these potential ways to improve the function of the product with significant reduction in the cost. The results of our study show that the traditional wooden Divan Bed serving the purpose of sitting and relaxing is evidently improved by adding functions of chair and table. We also observe the initial cost of the Divan Bed being Rs. 2026 has been enormously scaled down to Rs. 730 which is approximately $64 \%$ reduction in cost with further increase in functions. The introduction of polypropylene material has also eased the production process which leads to reduction in labour costs. With the proposed modifications in the design stages, the value of the product is thus enhanced leading to greater benefit. The further scope of the product is using Composite Materials.

\section{REFERENCES}

[1] Anil Kumar Mukopadhyaya (2018). Survey of Forty Years and Selected Essays".

[2] Gohil, Pooja \& Patel, Shaishav. (2018). Review of Value Engineering in Indian Construction Industry. 8.

[3] Amit Sharma, Harshit Srivastava, R.M. Belokar (2011). A Case Study Analysis Through the Implementation of Value Engineering, International Journal of Engineering Science and Technology (IJEST), Vol. 3, No. 3, ISSN: 0975-5462.

[4] Abdelghany, Mohamed \& Rachwan, Racha \& Abotaleb, Ibrahim \& Fathy, Amr \& Albughdadi, Ahmed. (2015). Value Engineering Applications to Improve Value in Residential Projects. 10.13140/RG.2.1.1820.1762. 
[5] Chakravarthy, Kalyan. (2018). A study on value engineering and green buildings in residential construction.

[6] Ghoushchi, Saeid \& Dorosti, Shadi \& Tehrani, Saeed. (2017). Characteristics of the research on value engineering (2000-2015). World Review of Science, Technology and Sustainable Development. 13. 10.1504/WRSTSD.2017.084171.

[7] Atabay, Senay \& Galipogullari, Niyazi. (2013). Application of Value Engineering in Construction Projects. Journal of Traffic and Transportation Engineering. 1. 10.17265/23282142/2013.12.005.

[8] Rad, Kaveh \& Yamini, Omid. (2016). The Methodology of Using Value Engineering in Construction Projects Management. Civil Engineering Journal. 2. 262. 10.28991/cej030986.

[9] Tohidi, Hamid. (2011). Review the benefits of using Value Engineering in Information Technology Project Management. Procedia CS. 3. 917-924. 10.1016/j.procs.2010.12.150.

[10] Channon, Derek. (2015). Value Engineering. 10.1002/9781118785317.weom120144.

[11] Heiza, Khaled \& Enen, Nagwan \& Mahdi, Ibrahim \& Hawas, Mohamed. (2015). VALUE ENGINEERING, VALUE ANALYSIS AND VALUE MANAGEMENT OF VERTICAL SLIP FORM CONSTRUCTION SYSTEM.

[12] Arumsari, Putri \& Tanachi, Ricco. (2018). Value engineering application in a high rise building (a case study in Bali). IOP Conference Series: Earth and Environmental Science. 195. 012015. 10.1088/1755-1315/195/1/012015. 